\title{
DIN ÎNSEMNĂRILE PROFESORULUI GHEORGHE CANTACUZINO (1900-1977). \\ III. SIMPOZIONUL NEOLITIC ORGANIZAT DE INSTITUTUL DE ARHEOLOGIE DIN BUCURESTI, ÎN ZILELE DE 30 NOIEMBRIE-2 DECEMBRIE 1972
}

GEORGE TROHANI

\author{
DES NOTES DU PROFESSEUR GEORGES CANTACUZENE (1900-1977). \\ III. LE SYMPOSIUM NEOLITHIQUE TENU PAR L'INSTITUT D'ARCHEOLOGIE \\ DE BUCAREST ENTRE LE 30 NOVEMBRE ET LE 2 DECEMBRE 1972.
}

Entre le 30 novembre et le 2 décembre 1972 l'Institut d'Archéologie de Bucarest a inauguré une série de symposia annuels concemant les divers époques de la préhistoire.

En ce qui suit, nous reproduisons les notes prises par le professeur Georges Cantacuzène (1900-1977) à cette occasion, inclusivement les discussions qui ont eu lieu.

Ainsi, le 1 décembre 1972 Nicolas Vlassa de Cluj a soutenu le rapport La plus ancienne céramique peinte néolithique du nord-ouest de la Transylvanie. Petreşti.

Le même jour Iuliu Paul a soutenu le rapport La céramique peinte du commencement de la civilisation

Le 2 décembre Eugène Comşa a présenté le rapport La chronologie relative et absolue de l'énéolithique en Roumanie.

Pour les autres rapports présentés au symposium il n`y a pas des notes. En échange il reste une Note concernant le Symposium Néolithique tenu le 30 novembre et le 1-2 décembre 1972 très critique en ce qui concerne l’organisation proprement-dite.

MOT CLEFS : néolithique, peinte céramique, chronologie

CUVINTE CHEIE : neolitic, ceramică pictată, cronologie

În zilele de 30 noiembrie-2 decembrie 1972, Institutul de Arheologie din București a inaugurat un şir de simpozioane anuale ce se doreau a lămuri diversele probleme ale cercetării preistorice din România. Începutul a fost făcut, cronologic, cu epoca neolitică, iar la dezbateri, pe lângă cercetătorii institutului bucureștean, au fost invitaţi specialiști din toată tara - din institutele Academiei, din muzee şi universităţi.

O prezentare succintă a acestui simpozion a fost făcută de către Eugen Comşa ${ }^{1}$. În cele ce urmează dorim a prezenta notele şi opiniile consemnate de către profesorul Gheorghe Cantacuzino păstrate în manuscrisele sale, care completează din plin cele publicate anterior.

În ziua de 1 decembrie 1972 cercetătorul clujean Nicolae Vlassa ${ }^{2}$ a prezentat raportul Cea mai veche ceramică pictată neolitică din nord-vestul Transilvaniei. Monografia arheologică a aşezării de la Gura Baciului va fi publicată în anul 1995, de către Gheorghe Lazarovici şi Zoia Maxim³ ${ }^{3}$, volumul fiind dedicat memoriei lui Nicolae Vlassa. Primele rânduri ale monografiei (pag. 1) sunt edificatoare: „Staţiunea de la Gura Baciului a însemnat şi înseamnă încă un punct de referinţă în cercetarea istoriei străvechi a primelor comunități etno-culturale neolitice timpurii. Nicolae Vlassa, prin publicarea amănunţită a importantelor sale articole $^{4}$ şi, mai ales, prin comunicarea pe care a susţinut-o la Bucureşti, în cadrul unui colocviu despre procesul de neolitizare, organizat de Institutul de Arheologie,

\footnotetext{
${ }^{1}$ Comșa 1973

${ }^{2}$ Nicolae Vlassa (20 noiembrie 1934-decembrie 1984) - cercetător, muzeograf şi șef de secţie la Muzeul de Istorie al Transilvaniei din Cluj-Napoca. A ţinut cursuri şi seminarii la Universitatea din Cluj-Napoca, precum şi la Institutul de Arte Plastice din aceeaşi localitate.

${ }^{3}$ Lazarovici Maxim 1995

${ }^{4}$ Vlassa 1972a; Vlassa $1972 b$
} 
a demonstrat indubitabil că procesul de neolitizare din România şi regiunea carpato-dunăreană este rezultatul unui proces de migraţie al unor comunităţi neolitice venite din regiune Thessaliei."

Profesorul Gheorghe Cantacuzino notează :

(Nicolae) Vassa-Cea mai veche fază a culturii Cris din Transilvania găsită în asezarea de la Gura Baciului. Comunicare la 1 decembrie 1972.

A exprimat indoieli asupra descoperirilor fácute la Dăita şi în alte locuri de la Ceahlău - Vl. Dumitrescu de curând a sustinut că cultura Criş este cel mai vechi neolitic din România.

Bordeiele foarte adânci şi căpăcuirea cu un strat steril, caracterul arhaic al materialelor ceramice, apariția obsidianei, infıma cantitate de ceramică cu barbotină găsite la Gura Baciului arată caracterul timpuriu al culturii.

S-a găsit un mormânt chircit, având ocru cu oase de om şi copil. S-au găsit și oase de copil sacrificat. Tipul antropologic este brahicefal diferit de tipul dolihocefal al scheletelor culturii Cris din alte faze.

In 1970 săpătura a găsit 3 niveluri de cultură Criș.

Stratigrafia : strat de păşune, sol de pădure, material arheologic $0-0,25 \mathrm{~m}$

$0,25-1,80 \mathrm{~m}$ straturi geologice sterile arheologic

$1,80-2 \mathrm{~m}$ Nivel III Cris

2-2,40 m Nivel II Cris

2,40-2,70 m Nivel I Criş, sol negru mătăsos.

Din nivelul I pornesc gropile de bordeie până la adâncimea de $3,70 \mathrm{~m}$.

Bordeiele apartin nivelului I, iar locuintele de suprafafă aparţin nivelurilor II şi III.

Materialele din nivelul I - materialul litic este compus in majoritate din obsidiană translucidă. Piesele sunt trapeze. S-a găsit şi un lustruitor de piatră in formă de papuc. S-a găsit o formă de topor.

2 piese din gresie nisipoasă folosite pentru a zdrobi ocrul.

9 sule și străpungătoare, din care una piesă putea fi un pumnal.

S-au găsit şi oase de măgar sălbatic.

Două obiecte din corn.

Scoici și melci fosili. Ín nivelul I s-a găsit l exemplar.

Un os humanum perforat.

Brățară fosilă din Pectunculus; brătara provine din specia fosilă aruncată pe nisipurile Mediteranei.

Un exemplar de valvă de scoica cardium, care este un exemplar rar în neolitic.

Ceramica de la Gura Baciului - s-a găsit numai ceramică fină şi foarte fină cuprinzând pleavă. Slipul este necunoscut în nivelul I; el apare numai în nivelul III.

$S$-au găsit vase mici, de foarte bună calitate, având reflexe metalice.

Materialul ceramic din nivelul I este foarte redus şi cuprinde 3 aspecte de vase: boluri, străchini in formă de calotă, vase globulare. Această ceramică este primitivă, cu forme reduse. Vasele mari de provizii lipsesc cu totul.

Decorul ceramic cu motive reduse: pastile, ornamente adâncite.

Decorul cardial apare pe un singur vas.

Decorul alveolat apare rar.

Ceramica pictată - este o specie de lux. Pictura un decor perfect - cu ornamente rare.

Buline ovoidale, rotunde, romburi inlănfuite. Ca analogie există ceramica din Backa, în JugoslaviaDonja Brazina.

In stratul No. 3 - această ceramică nu poate fi situată cronologic paralel cu stratul 2 aceramic de la Lepenski Vir, ci cu aceea din stratul 3 din Lepenski Vir. Autorul definește această ceramică ca un material neolitic vechi, necunoscut decât la Donja Brazina.

Plastica de lut de la Gura Baciului - sunt idoli zoomorfi şi antropomorfi. S-a găsit şi o piesă antropomorfă î formă de cui.

Plastica de piatră - sunt 3 piese mari arătând un bovideu şi 2 piese antropomorfe.

Capete de piatră - in nivelul I s-au găsit 15 bolovănaşi de piatră sculptafi cu figuri omeneşti - tofi provin din nivelul I, la 2,40-2,70 $\mathrm{m}$ şi sunt din calcar. Descrierea capetelor de piatră arată analogia lor cu Lepenski Vir. S-a fãcut o alegere deliberată a bolovanilor pentru a fi apoi sculptafí.

Un bolovan - figurează un cap cu ochiul stâng și 2 bendite. Este identic cu un cap găsit la Lepenski Vir. 
In Palestina, la Einoch, s-a găsit o piesă de piatră ornamentată.

Un cap are la orbita dreaptă o gaură adâncă.

Trebuie cercetat dacă tresele sculptate pe bolovanul din Lepenski Vir nu seamănă relativ cu arta din epoca culturii natufiene.

Mormintele culturii Criş I-schelet chircit de femeie, cu os de animal şi 2 bolovani de calcar.

Mormântul No. 3-schelet de copil - are lângă craniu 2 bolovani de calcar.

Mormântul No. 4-schelet de adult la -2,70 m. Este de femeie. S-a găsit un frecător de piatră.

Mormintele se găsesc sub podeaua bordeielor și au ca analogie acele de la Gura Baciului.

În nivelurile II si III de la Gura Baciului materialul arheologic este diferit.

Datarea complexului de la Gura Baciului

Nivelul II are analogii cu Karanovo I, Lepenski Vir 3, Starčevo II.

Nivelul III - materialul din Gura Baciului este contemporan cu Starčevo B2. Apare brâul alveolar, meandrul, zig-zag - elemente care vor deveni frecvente in ceramica liniară.

Prin comparafie se pot stabili caracteristicile nivelului $I$.

Migratorii au venit din nordul Tessaliei in nordul Transilvaniei, ei apartinând culturii Proto Sesklo A, mai de grabă decât Proto Sesklo B. Acest grup uman s-a desprins foarte recent de grupul uman rămas la Proto Sesklo.

Există deosebiri totuşi între decorul de la Gura Baciului şi din Backa (Dolja Brezina) - arată o migrare spre Ardeal in un loc cu o generatie mai inainte.

Sfârşitul culturii Lepenski Vir a fost provocat de migratorii culturii Criş I mergând la Gura Baciului.

Faza Lepenski Vir 2 care corespunde cu Gura Baciului I care au bolovani antropomorfi. Donja Brezina nu le mai are.

Decorul a fost executat prin cardiu.

Materialul de la Gura Baciului se leagă de Proto Sesklo prin materialul incă inedit de la Amzabegovo, păstrat in muzeul din Śtip.

$\mathrm{Nu}$ există materiale Cris anterioare culturii Proto Sesklo.

Cultura Cris nivel I cuprinde ultimele faze ale culturii Lepenski Vir.

Intrebări, discutii

(Marin) Cârciumaru arată că nivelul III Criş̧ este aşezat sub un sol ingropat. Solul steril este alunecat de pe pantă.

(Nicolae) Vlassa este de acord.

Silvia Marinescu indică faptul că ieri Vlassa a declarat că în stratul 2 Lepenski Vir s-a găsit ceramică şi astăzi afirmă că acest strat este aceramic şi că cultura Gura Baciului este posterioară.

Gh. Lazarovici - in Banat există o ceramică roşie a culturii Criș cuprinzând pleavă, care apartine fazei I. El declară că materialul găsit la Amzabegovo apartine unei faze târzii a culturii Vinča.

Ion Nestor observă că fazele culturii Criş nu sunt bine cunoscute și ca urmare să se facă cercetări.

Eugen Comşa aminteşte că în nord-vestul Bulgariei nu s-a găsit nici o cultură mai veche, din vremea culturii Starčevo-Criş. A fost însă găsită o cultură neolitică târzie, înrudită cu faza III a culturii Karanovo.

(Vladimir) Milojcic a infirmat că materialul din nivelul I de la Gura Baciului este similar cu acel de la Proto Sesklo.

(Marin) Nica arată că în aşezarea de la Cârcea a găsit un şant în care s-au găsit cranii separate fãră schelet. Materialul găsit de Nica este adus şi expus la Institut.

(Nicolae) Vlassa - trebuie să alegem între periodizarea lui M. Garasanin şi aceea a lui Milojcic.

(Nicolae) Ursulescu - a găsit o aşezare a culturii Criş în jud. Suceava. In nordul Moldovei nu există ceramică pictată în cultura Criş. S-a găsit un topor perforat. Crede că cultura Criş din Moldova a avut ofază mai târzie.

Silvia Marinescu afirmă că există cioburi Cucuteni A în jud. Suceava.

Dinu Marin şi E. Comşa amintesc că au constatat cioburi Precucuteni în Suceava.

În jud. Suceava se cunosc numai două stafiuni ale culturii ceramicii liniare. Lângă oraşul Suceava, aşezarea ceramicii liniare există în cartierul Şipot. În apropiere este aşezarea culturii Criş.

Tov. (Eugenia) Păpısşoiu arată că s-a găsit o unealtă perforată. Crede că au existat mai multe niveluri ale culturii Criş in Moldova. 
Tov. (Dan) Monah semnalează o aşezare a culturii Criş̧ in zona Bacăului, in localitatea Valea Trotusului cu ceramică pictată.

Tot în ziua de 1 decembrie 1972, Iuliu Paul ${ }^{5}$ a prezentat raportul Ceramica pictată de la începutul culturii Petrești. O prezentare monografică a acestei culturi va apărea peste 20 de ani ${ }^{6}$.

Profesorul Gheorghe Cantacuzino consemnează în notiţele sale:

\section{Iuliu Paul - Stadiul actual al culturii Petresti}

$S$ - a crezut că această cultură ar deriva din cultura Criş.

Acum a apărut o ceramică cu culoare albă, albă-gălbuie şi o altă ceramică cu fond galben.

Cercetările de la Lumea Nouã au complicat lucrurile, propunându-se solutii inexacte.

Motivele formau benzi.

În 1970 săpăturile au găsit 3 niveluri în aşezarea de la Daia Română.

In Transilvania nu există o fază Vinča A și Vinča B2, ci abia o fază Vinča C.

Cultura Petreşti este sincronã cu cultura Cucuteni A, insă faza Petreşti de la Daia este ceva anterioară fazei Cucuteni A. Cultura Petreşti A a fost precedată de ceramica pictată de la Daia Română, însă aceasta nu este generatoarea ceramicii Petreşti A.

Ceramica pictată de la Lumea Nouă este de asemeni diferită. Nu se cunoaşte încă relația lor precisă cu ceramica pictată Petreşti A şi cu ceramica pictată de la Daia Română.

Ion Nestor arată că nu avem incă o bază pentru a fixa periodizarea culturii Ariuşd; aceasta însă fãcea legătura intre culturile Cucuteni şi Petreşti. Deci nu se poate (stabili) deocamdată relajia intre culturile Cucuteni şi Petreşti A.

Iuliu Paul declară că admite influente venite din sud-vest, prin Iugoslavia.

Cultura Lumea Nouă nu depăşşste faza Vinča B2.

În ziua de 2 decembrie Eugen Comşa ${ }^{7}$ a prezentat raportul Cronologia relativă şi absolută a eneoliticului din România. Profesorul Gheorghe Cantacuzino notează:

\section{Eugen Comşa - Cronologia relativă si absolută a culturilor neolitice.}

1) Exprimă părerea că importurile de piese de aramă nu au avut o inrâurire asupra dezvoltării culturilor neolitice; dezvoltarea lor s-a fácut intens şi independent.

2) Trecerea s-a făcut fără întrerupere de la cultura Boian la cultura Gumelniţa. Faza de trecere a avut după E. Comşa 2 etape.

3) După faza Boian V corespunde cu Precucuteni III.

(n.n. Numerotarea indicată respectă notițele olografe.)

6) Faza Varna reprezintă tranzifia de la faza III Hamangia la faza Gumelnifa I.

7) Contestă periodizarea culturii Precucuteni - contestă alipirea fazei Precucuteni III de faza Tripolje A. Cultura Precucuteni I şi chiar Precucuteni III au fost in anumite locuri sincrone cu cultura Bugo-Nistriană.

8) Culturile Precucuteni si Tripolje A sunt deosebite.

9) Nu se ştie ce a existat intre cultura Precucuteni III şi cultura Boian faza Aldeni în sudul Moldovei.

10) Este neclară situaţia neoliticului în nord-vestul Transilvaniei. Aici au existat comunitățile culturii Ciumești.

\footnotetext{
${ }^{5}$ Iuliu Paul (18 august 1930-4 noiembrie 2009) - cercetător, muzeograf, şef de seç̧ie şi director ştiinţific al Muzeului Brukenthal din Sibiu. Își va încheia cariera științifică ca profesor şi rector al Universităţii „1 Decembrie 1918” din Alba Iulia.

${ }^{6}$ Paul 1992

${ }^{7}$ Eugen Comşa (20 octombrie 1923-7 noiembrie 2008) - cercetător ştiinţific, şef de secţie la Muzeul Nał̧ional de Antichităţi şi apoi la Institutul de Arheologie „Vasile Pârvan” din București.
} 
11) Periodizarea culturii Vinča nu mai corespunde cu progresele culturilor neolitice din Muntenia, Oltenia şi Banat.

12) În privinfa culturii Vădastra periodizarea nu este încă stabilită definitiv. D. Berciu a stabilit după săpături la Slatina 4 faze ale culturii Vădastra. Nica a stabilit de asemeni 4 faze ale ei-faza I Vădastra este sincronă cu faza I Boian; în faza II Vădastra s-au găsit materiale similare cu faza II Boian. S-au mai găsit încă materiale indicând o fază III de sfârşit.

3 bis) Cultura Gumelnita - D. Berciu a stabilit 4 faze, la Tangâru. Succesiunea este acceptată. Este insă greşită metoda de a periodiza o cultură Gumelnita pe baza săpăturii de la Tangâru.

Se cere analiza tuturor materialelor arheologice a acestei culturi din orice locuire.

4) Cultura Cucuteni-periodizarea acestei culturi făcută in 1932 de H. Schmidt a rămas valabilă. S-au impărtit apoi fazele în etape.

Noua periodizare a fost făcută de Vl. Dumitrescu.

Faza Cucuteni $A$ in 4 etape A, B, C, D. Faza Cucuteni $A-B$ in 2 etape. Faza Cucuteni $B$ in 4 etape.

$E$. Comşa critică localizarea geografică a fazelor şi a etapelor culturii Cucuteni.

Cere să se intercaleze şi o fază Huşi.

Crede că aşezările din Moldova atribuite culturii Cucuteni şi ...(neclar) evoluția spre cultura Monteoru trebuie grupate separat.

5) Relaftii dintre culturile Cucuteni şi Gumelniţa

E. Comşa arată că sincronisme anumite stabilite de Vl. Dumitrescu în fazele Gumelnifa $A-B$ şi Gumelniţa B şi cultura Cucuteni sunt greşite.

Există o inegalitate vizibilă şi clară între dezvoltarea culturii Gumelniţa şi aceea a cultura Cucuteni. Ori a doua cultură a fost prea lungită, ori prima cultură a fost în mod greşit scurtată.

6 bis) Descoperirea unui mormânt la Ravna continând vestigii ale populatiilor nomade ale culturii cu ocru dovedește pătrunderea începutului acestei migratii de nomazi încă din vremea fazei Cucuteni $A$.

7 bis) Aspectul Ariuşd al culturii Cucuteni din zona de est şi centru a Transilvaniei a avut o evolufie deosebită în vremea fazelor Cucuteni $A-B$.

8 bis) Contestă sincronismele stabilite de Paul intre culturile Cucuteni şi Petreşti - problema a fost discutată in ziua de 1 dec. 1972.

10 bis) S-au stabilit de mult paralelisme intre evolutia culturii Gumelnifa A şi cultura Petreşti.

11 bis) Cultura Sălcuta a evoluat paralel aproape cu cultura Gumelniţa, aceasta fiind putin anterioară.

12 bis) Se arată că deşi câteva periodizări sunt greşite, E. Comşa a trebuit să fie utilizată.

\section{Cronologia absolută a culturilor neolitice din România}

După Vl. Dumitrescu

Cucuteni faza Gumelnita B incepe în 1500 i.e.n. cu continuare până în Bronz

Gumelnita Aera datată pe la 2.400 i.e.n.

Pe la 1948 cele mai vechi culturi neolitice erau datate în mileniul III î.e.n.

\section{E. Comsa}

Acum se folosește metoda Carbon 14 şi metoda dendrocronologică.

$S$ - a ajuns la concluzia că intre ele există o diferenţă de 1.000 ani in plus pentru metoda Carbon 14 fałă de cea dendrocronologică data de 4.000 i.e.n.

\section{Datări obtinute}

Pt cultura Boian 3.900-3.920

Pentru cultura Boian faza Greaca sincronă

cu cultura Precucuteni I 4.200

Inceputul culturii Boian (Bolintineanu) 4.400

Cultura Hamangia faza III sincronă

cu faza Vidra 3.950

cultura Precucuteni A 3.600 
In Bulgaria

La Hotnita $\pm 3.610 \pm 100$

Karanovo $\pm 3.700-3.600$

Cucuteni A 33.400

Cultura Vinča C 3.600

Vinča $D 3.500$

\section{Discuţii în ziua de 2 XII 1972 asupra raportului lui E. Comşa}

1) Mircea Petrescu-Dâmbovita cere să fie folosit termenul eneolitic.

Prin contradicfie E. Comşa, care contestă termenul eneolitic, admite o perioadă de tranzifie intre culturile Boian și Gumelnita.

Toporul de cupru găsit la Glina conține aproape cupru pur, 0,1\% părti străine.

2) Este justă concluzia pusă de E. Comşa că periodizarea unei culturi trebuie fãcută după săpături în mai multe aşezări. Pentru cultura Gumelnita nu s-a făcut o analiză de acest fel.

3) În privinta culturii Cucuteni, fazele si etapele nu sunt sigure.

Pentru Cucuteni $A$ nu se poate face periodizarea etapelor $A 2$ și A3 decât la Cucuteni, deoarece sub acestea există stratul de cultură Truşeşti.

4) Venirea migratorilor - popoare nomade de la est - a inceput chiar în faza Cucuteni $A$ şi a continuat in acea $A-B$.

Troia I

Troia II început 3.200 i.e.n. pe baza analizei de cereale prin radiocarbon.

Cernavoda I datată pe la 2.300 î.e.n.

Epoca de tranzifie - 2.300 i.e.n.

S(ebastian) Morintz - saltul calitativ s-a produs la sfârşitul Boian II în Muntenia, in neolitic. Propune să se impartă îtregul neolitic românesc în două faze : I anterior cu populatii semistabile şi alta II după faza II Boian (Giulești) cu populatii sedentare.

a) Perioada de tranzifie este mult mai lungă, de cât se credea, la sfârş̧itul neoliticului - dispariftia ceramicii pictate.

În cursul culturii Cucuteni A-B pătrunseseră deja migratori nomazi.

După ce cultura Cernavoda I a ocupat Câmpia Dunării, dealurile Munteniei erau ocupate de alte culturi, adică încă de triburi Sălcufa.

N. Vlassa - a) arată că se cere uniformizarea datelor cronologice folosite în arheologia României şi o uniformizare a termenilor arheologici.

b) cere să se introducă şi termenul de topor de tip ... (nerefinut)

c) este convins de sincronismul culturii de la Decea Mureşului cu cultura Bodrog Keresztur aşezarea din acest loc aparfine unor migratori veniţi din sudul URSS, a culturii din necropola de la Mariupol.

Silvia Marinescu(-Bîlcu) - în Transilvania avem numai pătrunderea culturii Cucuteni I, nu Precucuteni II.

Există in cultura Gumelnita materiale precucuteniene prelucrate pe loc.

Arată similitudini perfecte: tehnică, pastă, ardere, forme intre materiale din faza Precucuteni III şi Tripolje A. Delimitarea s-a fácut in faza Tripolje B.

Doina Galbenu - sustine că cultura Sălcuța este deosebită de cultura Gumelniţa.

S. Morintz susfine că (Sălcufa) este o variantă a aceleaşi culturi Gumelnifa. Materiale Sălcufa IV se aseamănă cu cultura Cernavoda III.

Eugenia Zaharia - susţine că aspectul cultural Ariuşd este deosebit de cultura Cucuteni.

Dinu Marin - a) cere să se publice o lucrare mai amplă cu privire la cultura Gumelniţa

b) in zona Huși - Vaslui sunt materiale arătând nașterea fazei Cucuteni $A-B$

c) cimitire de-a lungul Nistrului apartin fazei Cucuteni $C=$ Foltești-Usatovo 
d) ruşii au arătat că mormintele tumulare sunt post-usatoviene

e) aria culturii Cucuteni

N. Vlassa arată: a) mormintele plane cu ocru nu se cunosc în Transilvania, (sunt) numai tumulare.

b) Târgul Mureș este punctul extrem spre vest ale culturii Decea Mureşului.

c) aspectul Ariusd al culturii Cucuteni a avut o evolufie lungă.

d) chiar la Ariussd s-au găsit fragmente ceramice ale culturii Cucuteni A4.

e) la Drăguşeni s-a găsit o variantă locală a culturii Cucuteni $A-B$.

Câti idoli s-au găsit în România?

Idolii apar la sfârşitul Troia I.

Idolii apar la Rachmani în Grecia.

Troia I anatoliană are o cultură proprie pe coastă si în Europa. Alta este evolutia acestei culturi, care la Milojcici atinge faza Troia IV. Cucuteni $C$.

Petre Roman arată că cultura Cernavoda I cuprinde așezări diferite contaminate cu unele elemente

(Gheorghe) Lazarovici - a) combate ideea creării unei alte periodizări a culturii Vinča cerută de E. Comşa. Dacă s-ar face o nouă periodizare s-ar aduce ca faze pentru cultura Vinc̆a.

b) combate ideea că nu ar exista faza Vinc̆a C în Banatul românesc, însă ea există în Banatul iugoslav. Faza Vinča C cuprinde un nou impuls sudic venit în Banatul iugoslav.

c) după cultura Starčevo urmează în Banat cultura Vinča.

Ion Nestor relevă că periodizarea culturii Criş este, după unii cercetători, nesigură şi insuficient dovedită.

Eugenia Zaharia contestă unele pretinse relaţii între faza II Boian (Giulești) și Precucuteni II.

Pentru celelalte rapoarte prezentate nu există relatări. Probabil că Gheorghe Cantacizino nu lea audiat. Ne referim la cuvântul de deschidere rostit de D.M. Pippidi, directorul Institutului, Ion Nestor, Problema începutului neoliticului pe teritoriul R.S. România, Vasile Boroneanţ, Cultura Schela Cladovei, Corneliu N. Mateescu, Agricultura în neolitic la Vădastra și în regiune şi Alexandru Vulpe, Începuturile metalurgiei aramei în România.

În schimb s-a păstrat ciorna unei note critice referitoare la modul de desfăşurare a simpozionului. Dacă a fost dactilografiată şi înaintată altor foruri academice nu ştim.

\section{Notă privind Simpozion(ul) Neolitic tinut la 30 XI ssi 1-2 Decembrie 1972}

Simpozionul a avut grave deficiente, anume:

1) A fost prost pregătit deoarece:

a) Toate rapoartele şi comunicärile nu au fost reproduse la xerox sau dactilografiate spre a fi difuzate inainte.

b) Această deficientă contravine dispozifiunilor precise date de Consiliul Ştiintific în şedinfa din 22 ianuarie 1972, când s-a hotărât ca toate lucrările supuse examinării să fie difuzate mai inainte.

c) $\mathrm{Nu}$ a fost adus nici un magnetofon, care să inregistreze atât textul rapoartelor, cât și discuţiile şi obiectele aduse - argumentat că megafonul folosit în 1971 şi aparținând Institutului ar fi defect, nu e valabil, căci Tov. Ion Nestor şi E(ugen) Comşa, organizatorii simpozionului, trebuiau să se ocupe din timp să repare acest magnetofon sau să procure un altul. Simpozionul se putea tine chiar în sala Institutului de Istorie.

2) O deficientă gravă este că Ion Nestor care a prezidat acest colocviu a venit total nepregătit - nu a depus un raport dactilografiat, ci a făcut o expunere verbală, intemeiat(ă) pe unele note. Din expunerea sa, care trebuia să privească originea neoliticului în tara noastră, nu s-a ințeles nimic.

Informatia sa a fost slabă, incompletă - despre creșterea animalelor domestice a declarat că nu $e$ dovedit că a existat încă de la sfârșitul mezoliticului şi că oasele de oaie găsite in unele statiuni mezolitice pot fi ale unor oi domesticite fugite din aria culturilor neolitice situate în părtile sudice ale Europei şi devenite sălbăticite. 
Această teză a fost formal contrazisă de Tov. Samson şi Rădulescu pentru oasele de oaie găsite in stratul cel mai vechi, datând din mezolitic, la Peştera Adam odată cu inventar litic mezolitic. Tov. Samson şi Rădulescu au arătat că cantitatea de oase de oaie găsite în acest strat este mai redusă, dar că ele sunt în masse mari in stratul următor, care poate fi un protoneolitic, lipsit de ceramică şi au precizat că oaia a existat în stare sălbatică în mare număr în Dobrogea şi că a fost domesticită la sfârşitul mezoliticului. (Ei) au respins teoria lui Nestor privind fuga unor oi domesticite și revenite la sălbăticie.

În rezumat, Nestor nu a arătat cum au apărut treptat componentele neoliticului: creşterea animalelor domesticite şi cultivarea plantelor, dacă au fost introduse înainte de culturile neolitice, incă din mezolitic, dacă au crescut pe baze autohtone sau au fost introduse din regiunea mediteraneană a Asiei Mici în fara noastră.

3) Comunicarea lui V(asile) Boroneant a dovedit utilizarea de instrumente din corn - săpăligi ? - incă din mezolitic pentru cultivarea plantelor, ceea ce arată această ocupatie în acea vreme în cultura Schela Cladovei.

4) O gravă deficientă a fost lipsa oricăror concluzii ce se puteau trage din finerea acestui simpozion. Această obligatie era impusă lui Ion Nestor și el nu a onorat-o. Intr-adevăr. după încheierea discutiilor asupra referatului lui E. Comşa, sedinţa a fost închisă şi participantii au plecat fără a auzi o cuvântare sintetică şi călăuzitoare de incheiere a colocviului.

5) Referatul Tov. E. Comşa despre „Cronologia relativă şi absolută a culturilor neolitice” Irebuia neapărat difuzat mai înainte. Nu s-a procedat astfel; nu a fost timp suficient ca să fie citit întregul referat - a fost prezentat de E. Comşa numai un rezumat după el, căruia i s-au adus numeroase obiecfii.

6) In rezumat colocviul a fost inoperant, din cauza conditillor in care s-a finut. Au fost invitati si deplasafi circa 25 de cercetători din provincie, din care 10 au venit pe contul Institutului de Arheologie. Insă obiectiile, părerile lor nu au fost înregistrate la magnetofon, ceea ce împiedică chiar publicarea lor.

\section{BIBLIOGRAFIE}

Comşa 1973

Lazarovici Maxim 1995

Paul 1992

Vlassa 1972a

Vlassa 1972b
E. Comșa, Simpozionul neolitic, SCIV, 24, 1973, 2, p. 364-365

Gh. Lazarovici, Zoia Maxim, Gura Baciului. Monografie arheologică, ClujNapoca, 1995

I. Paul, Cultura Petrești - monografie arheologică, București, 1992

N. Vlassa, Cea mai veche fază a complexului cultural Starčevo-Criş în România, $\operatorname{ActaMN}, \mathrm{IX}, 1972$, p. 7-28

N. Vlassa, Eine frühneolitische Kultur mit bemalter Keramik der Vor-StarčevoKörös Zeit in Cluj-Gura Baciului, Siebenbürgen, $P Z$, 47, 1972, 2, p. 174-197

GEORGE TROHANI

Muzeul Naţional de Istorie a României, Calea Victoriei 12, sector 2, Bucureşti gtrohani@yahoo.com 